\title{
Gastrointestinal bleeding increases the risk of subsequent cardiovascular events in patients with acute cardiovascular diseases requiring intensive care
}

\author{
Shin Sakai ${ }^{1}$. Shuhei Tara ${ }^{1}{ }^{10} \cdot$ Takeshi Yamamoto $^{1} \cdot$ Kazuhiro Asano $^{1} \cdot$ Tokuhiro Kimura $^{1} \cdot$ Yuhi Fujimoto ${ }^{1}$. \\ Reiko Shiomura $^{1}$. Junya Matsuda ${ }^{1} \cdot K_{0}$ osuke Kadooka ${ }^{1} \cdot K_{\text {Kenta Takahashi }}{ }^{1} \cdot$ Toshinori Ko $^{1} \cdot$ Hideto Sangen $^{1}$. \\ Yoshiyuki Saiki ${ }^{1}$ Jun Nakata ${ }^{1}$. Yusuke Hosokawa ${ }^{1}$ - Hitoshi Takano ${ }^{2}$. Wataru Shimizu ${ }^{1,2}$
}

Received: 7 December 2020 / Accepted: 26 February 2021 / Published online: 8 March 2021

(c) Springer Japan KK, part of Springer Nature 2021

\begin{abstract}
Gastrointestinal (GI) bleeding worsens the outcomes of critically ill patients in the intensive care unit (ICU). Owing to a lack of corresponding data, we aimed to investigate whether GI bleeding during cardiovascular-ICU (C-ICU) admission in acute cardiovascular (CV) disease patients is a risk factor for subsequent CV events. Totally, 492 consecutive C-ICU patients (40.9\% acute coronary syndrome, 22.8\% heart failure) were grouped into GI bleeding ( $n=27 ; 12$ upper GI and 15 lower GI) and non-GI bleeding ( $n=465)$ groups. Thirty-nine patients died or developed CV events during hospitalization, and 453 were followed up from the date of C-ICU discharge to evaluate subsequent major adverse CV events. The GI bleeding group had a higher Acute Physiology and Chronic Health Evaluation II score $(20.2 \pm 8.2$ vs. $15.1 \pm 6.8, p<0.001)$, higher frequency of mechanical ventilator use $(29.6 \%$ vs. $13.1 \%, p=0.039)$, and longer C-ICU admission duration (8 [5-16] days vs. 5 [3-8] days, $p<0.001$ ) than the non-GI bleeding group. The in-hospital mortality rate did not differ between the groups. Of those who were followed-up, CV events after C-ICU discharge were identified in $34.6 \%$ and $14.3 \%$ of patients in the GI and non-GI bleeding groups, respectively, during a median follow-up period of 228 days ( $\log \operatorname{rank}, p<0.001)$. GI bleeding was an independent risk factor for subsequent CV events (adjusted hazard ratio: 2.23, 95\% confidence interval: 1.06-4.71; $p=0.035$ ). GI bleeding during C-ICU admission was independently associated with subsequent CV events in such settings.
\end{abstract}

Keywords Gastrointestinal bleeding · Cardiovascular event · Cardiovascular-intensive care unit

\section{Introduction}

Gastrointestinal (GI) bleeding is a commonly reported complication in critical care settings and occurs predominantly due to stress-related mucosal damage of the GI tract [1-3]. Moreover, aggressive anti-thrombotic therapies for patients with acute cardiovascular (CV) diseases, such as acute coronary syndrome (ACS), heart failure, and pulmonary embolism, aggravate the degree of GI bleeding in

Shuhei Tara

s5062@nms.ac.jp

1 Division of Cardiovascular Intensive Care, Nippon Medical School Hospital, 1-1-5, Sendagi, Bunkyo-ku, Tokyo 113-8603, Japan

2 Department of Cardiovascular Medicine, Nippon Medical School, Tokyo, Japan cardiovascular-intensive care units (C-ICU). Furthermore, GI bleeding may decrease the mortality rate of critically ill patients [4] and increase the risk of subsequent $\mathrm{CV}$ events in ACS patients [5, 6]. However, it is still unclear whether GI bleeding in patients with acute $\mathrm{CV}$ diseases, including nonACS disease, in the C-ICU is a risk factor for subsequent $\mathrm{CV}$ events. Therefore, this study aimed to investigate the association between GI bleeding during C-ICU admission and $\mathrm{CV}$ events after $\mathrm{C}$-ICU discharge in patients with acute $\mathrm{CV}$ disease.

\section{Methods}

\section{Study population}

We retrospectively reviewed hospital records and enrolled 492 consecutive patients who were emergently admitted 
to the C-ICU of Nippon Medical School Hospital for suspected acute CV disease between January 2018 and December 2018. The medical ethics committee of Nippon Medical School Hospital reviewed and approved this clinical study (B-2020-156). Opt-out consent by posting the research information in our hospital was utilized instead of obtaining informed consent from each patient because of our retrospective study design.

The 492 C-ICU patients comprised 201 (40.9\%) with ACS (126 with ST elevation myocardial infarction, 46 with non-ST elevation myocardial infarction, and 29 with unstable angina), $112(22.8 \%)$ with heart failure, $33(6.7 \%)$ with acute aortic dissection, 31 (6.3\%) with emergency arrhythmias, 12 (2.4\%) with Takotsubo cardiomyopathy, 7 (1.4\%) with acute myocarditis, $4(0.8 \%)$ with pulmonary embolism, and $92(18.7 \%)$ with other diseases. The patients were grouped according to the presence of GI bleeding during C-ICU admission into the GI bleeding group $(n=27)$ and the non-GI bleeding group $(n=465)$.

Thirty-four patients died, and 5 developed CV disease during the index hospitalization, and the remaining 453 patients were followed-up from the date of C-ICU discharge in order to evaluate subsequent $\mathrm{CV}$ events. The median follow-up period was 228 (interquartile range [IQR]: 30-353) days.

\section{Diagnosis of GI bleeding}

According to the Thrombolysis In Myocardial Infarction (TIMI) bleeding criteria [7], clinically apparent signs of bleeding, including imaging findings, with a reduction in the hemoglobin level, during C-ICU admission, were regarded as bleeding complications in this study. GI bleeding was defined as a bleeding complication that met the TIMI bleeding criteria and was observed by upper or lower GI endoscopy, or an episode of coffee ground emesis, hematemesis, melena, or red blood per rectum [5]. The severity of the bleeding complications was classified as follows: major, minor, or minimal, based on the TIMI bleeding criteria [7], and the bleeding complication onset date was determined as the day on which the TIMI bleeding criteria were satisfied. When a patient experienced multiple bleeding complications, the most severe bleeding event, as assessed by the TIMI bleeding criteria, was taken as the bleeding complication for the purpose of this analysis.

\section{Patient disease severity}

For the evaluation of disease severity on C-ICU admission, we applied two scoring systems: The Sequential Organ Failure Assessment (SOFA) score and the Acute Physiology and Chronic Health Evaluation (APACHE) II score. The SOFA score was used to quantitatively assess the presence of major organ dysfunction, including that of the respiratory, $\mathrm{CV}$, hepatic, coagulation, renal, and neurological systems. For each patient, the general disease severity was assessed according to the APACHE II score, based on 12 physiologic variables, age, and underlying health.

\section{Patient treatments}

C-ICU admission and discharge were determined by the fulltime attending CV intensivists. Treatment strategies, including intensive care for patients with emergency CV disease, in our C-ICU were planned and performed as indicated by guidelines. A stress ulcer prophylaxis strategy with oral or intravenous administration of proton pump inhibitors (PPIs) was applied for all patients admitted to our C-ICU unless they had contraindications according to recent ACS guidelines $[8,9]$.

\section{Endpoint and in-hospital adverse events}

For the evaluation of subsequent $\mathrm{CV}$ events after C-ICU discharge, the primary endpoint of the current analysis was defined as a composite of major adverse CV events (allcause mortality, non-fatal myocardial infarction or stroke, admission for heart failure, unstable angina, or other CV events) [10].

Nosocomial pneumonia and Clostridium difficile infection during hospitalization were selected as in-hospital infectious adverse events related to GI bleeding and PPI administration. In-hospital mortality was defined as short-term mortality of C-ICU patients.

\section{Statistical analysis}

Statistical analysis was performed with IBM SPSS Statistics version 25.0 software (SPSS Inc., Chicago, IL). Dichotomous variables were tested using the Fisher's exact test. Numeric values are presented as the means \pm standard deviations or the medians [IQR] and were tested using the Student's $t$ test or the Mann-Whitney $U$ test when the data had a non-normal distribution. The Kaplan-Meier method was used to estimate the cumulative incidence of the outcomes, and the differences were compared using the logrank test. For multivariate analysis, hazard ratios (HRs) and 95\% confidence intervals (CIs) for the risk of each outcome were determined by Cox proportional hazards modeling, and covariates including the APACHE II score, which served as the severity score at admission, use of mechanical support devices during the C-ICU stay (ventilator, renal replacement therapy, intra-aortic balloon pump, percutaneous cardiopulmonary support, and Impella ${ }^{\circledR}$ ), and length of C-ICU stay were selected through consideration of their impact on the outcomes at each time-point, in addition to age, sex, primary 
disease, and GI bleeding. A probability $(p)$ value $<0.05$ was considered indicative of a statistically significant difference.

\section{Results}

\section{Frequency and severity of GI bleeding}

Bleeding complications developed in 64 of the 492 patients (13.0\%) during C-ICU admission. Among those with bleeding complications, GI bleeding was the most frequently reported bleeding type, as observed in 27 of the 492 patients (5.5\%; 12 with upper GI bleeding and 15 with lower GI bleeding), followed by puncture site bleeding ( $4.7 \%)$, cardiac origin bleeding $(1.0 \%)$, intra-cranial bleeding $(0.8 \%)$, respiratory tract bleeding $(0.4 \%)$, major blood vessel bleeding $(0.2 \%)$, and others $(0.4 \%)$.

GI bleeding was observed by upper GI endoscopy in 11 patients and by lower GI endoscopy in 6 patients. The clinical episodes of GI bleeding included 3 with coffee ground emesis or hematemesis, 9 with melena, and 15 with red blood per rectum. In terms of the severity of GI bleeding, the rates of major, minor, and minimal bleeding were 25.9, 44.4 , and $29.6 \%$, respectively. Minor upper GI bleeding and minimal lower GI bleeding were most frequent (upper GI bleeding: major $33.3 \%$, minor $58.3 \%$, minimal $8.3 \%$; lower GI bleeding: major $20.0 \%$, minor $33.3 \%$, minimal $46.7 \%$ ). The frequencies of GI bleeding, with their severity for each primary disease, are shown in Fig. 1a. Details on the timing of complications of GI bleeding during C-ICU admission are presented in Fig. 1b. The frequencies of GI bleeding on the first day and within 5 days of hospitalization were $33.3 \%$ $(n=9)$ and $77.8 \%(n=21)$, respectively.

\section{Patient characteristics and treatments}

We compared the characteristics and co-interventions used during the C-ICU admission period between the patients in the GI bleeding and non-GI bleeding groups (Table 1). There was no statistical difference in patient demographics between the groups (age, $72.3 \pm 14.9$ vs. $70.8 \pm 14.6$, $p=0.592$; female sex, 44.4 vs. $34.8 \%, p=0.309$ ). The use of anti-platelet drugs before admission was not associated with the occurrence of GI bleeding. The administration rate of anti-peptic ulcer drugs, including PPIs and histamine type 2 receptor antagonists $\left(\mathrm{H}_{2} \mathrm{Ras}\right)$, before admission, which were considered for prophylaxis against low-dose aspirin ulcers or treatment of peptic comorbidities, such as gastritis and gastric ulcer, showed no statistically significant difference between the groups (PPIs, 33.3 vs. $29.5 \%, p=0.668 ; \mathrm{H}_{2} \mathrm{Ras}$, 3.7 vs. $3.9 \%, p=1.000$ ). Furthermore, when the administration rates were compared between patients with upper and lower GI bleeding among the GI bleeding group, no statistically significant difference was observed (PPIs, 25.0 vs. $40.0 \%, p=0.683 ; \mathrm{H}_{2}$ Ras, 0 vs. $\left.6.7 \%, p=1.000\right)$. The GI bleeding group showed higher proportions of out-of-hospital cardiac arrest ( 18.5 vs. $3.2 \%, p=0.003)$ and shock vitals on arrival ( 25.9 vs. $10.8 \%, p=0.027)$. The severity scores on admission were significantly higher in patients with GI bleeding than in those without (SOFA score: $4.3 \pm 3.6$ vs. $2.8 \pm 3.2, p=0.016$; APACHE II score, $20.2 \pm 8.2$ vs. $15.1 \pm 6.8, p<0.001)$. The rate of PPI administration in the GI bleeding group increased to $100 \%$ during the C-ICU stay, regardless of upper or lower GI bleeding; patients without GI bleeding also had a high rate of PPI administration (82.6\%) based on the stress ulcer prophylaxis strategy in our C-ICU.

Blood transfusions were more frequently performed in patients with GI bleeding than in those without (81.5 vs. $17.6 \%, p<0.001)$. Mechanical ventilators were more commonly used in the GI bleeding group than in the non-GI bleeding group (29.6 vs. $13.1 \%, p=0.039$ ). Patients with GI bleeding had longer durations of C-ICU stay than those without (8 [IQR 5-16] days vs. 5 [IQR 3-8] days, $p<0.001$ ). However, there were no differences in infectious complications, including pneumonia and Clostridium difficile infection, during hospitalization and in-hospital mortality between the groups.

\section{Impact of GI bleeding on subsequent CV events}

After the exclusion of 39 patients who died or developed CV events during the index hospitalization, we assessed the rate of GI bleeding during C-ICU admission as a risk factor for subsequent $\mathrm{CV}$ events through follow-up of the remaining 453 patients from the date of C-ICU discharge. CV events were identified in $34.6 \%$ ( 9 of 26) of the patients in the GI bleeding group (25.0 and $46.7 \%$ of those with upper and lower GI bleeding, respectively) and 14.3\% (61 of 427) of those in the non-GI bleeding group. Kaplan-Meier analyses showed that the cumulative incidence of $\mathrm{CV}$ events was higher in the GI bleeding group than in the non-GI bleeding group (log-rank test, $p<0.001$ ) (Fig. 2). Upon evaluation of CV disease outcomes, statistically significant differences were observed in other $\mathrm{CV}$ events between the two groups (all-cause mortality: 3.8 vs. $1.9 \%, p=0.415$; non-fatal MI or stroke: 0.0 vs. $0.2 \%, p=1.000$; admission for heart failure: 15.4 vs. $5.6 \%, p=0.068$; unstable angina: 0.0 vs. $0.5 \%$, $p=1.000$; other CV events: 15.4 vs. $4.9 \%, p=0.047$ ). In the GI bleeding group, the patients who did not receive blood transfusion experienced no CV events, while $42.9 \%$ of those who received blood transfusion developed $\mathrm{CV}$ events $(p=0.129)$.

In the subgroup analysis of ACS $(n=190)$ and nonACS $(n=263)$ patients, the incidence of GI bleeding did not differ significantly ( 6.0 vs. $5.2 \%, p=0.693)$, and the cumulative incidence of $\mathrm{CV}$ events in both subgroups was 

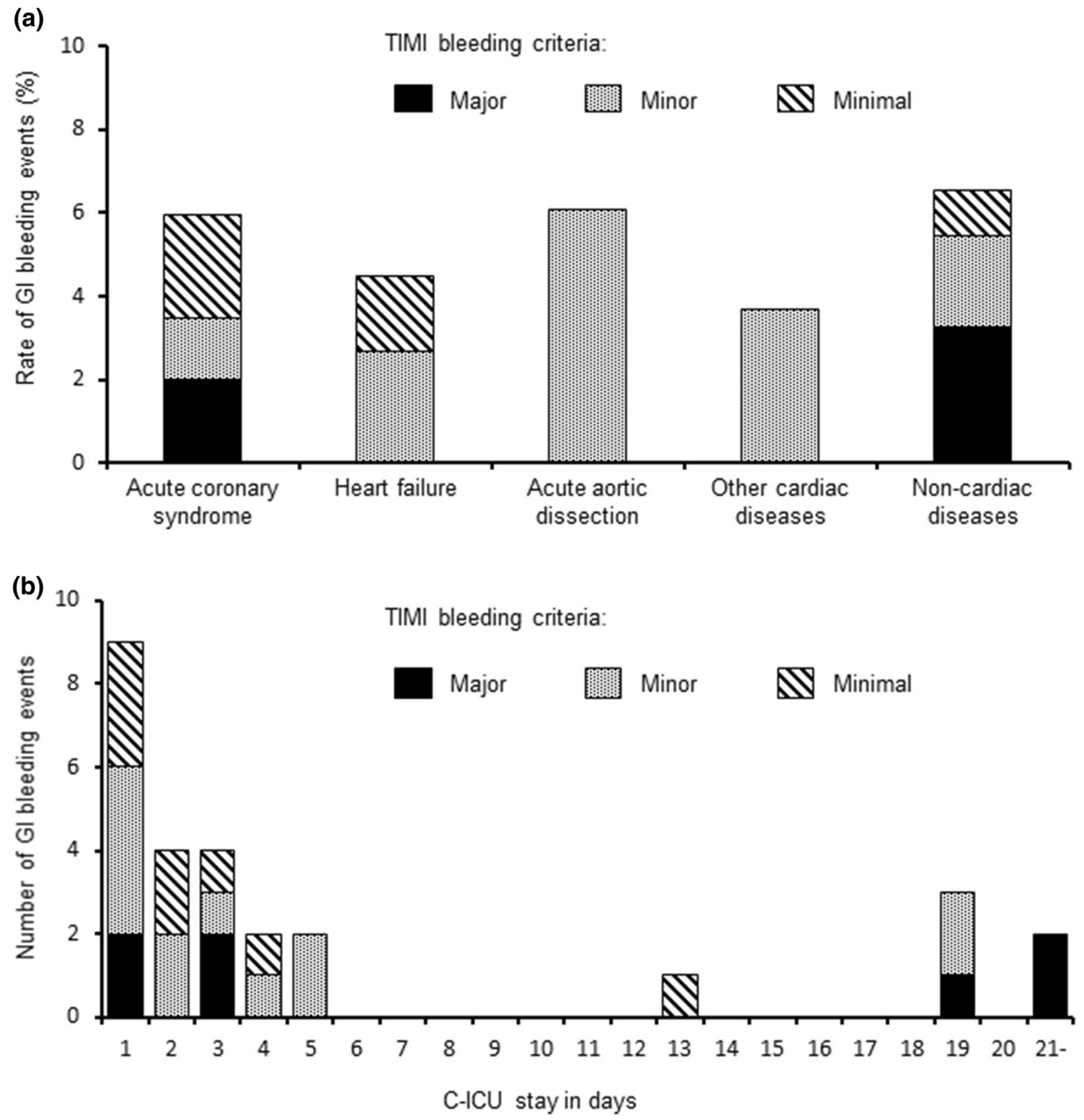

Fig. 1 a Incidence rate of GI bleeding for each primary disease, and b timing of GI bleeding complications during C-ICU admission. TIMI thrombolysis in myocardial infarction, GI gastrointestinal, $C$-ICU cardiovascular-intensive care unit

significantly higher in patients with GI bleeding than in those without (log-rank test, ACS: $p=0.002$; and nonACS: $p=0.022$, respectively).

Multivariable analysis employing Cox proportional hazards models revealed GI bleeding to be an independent risk factor for $\mathrm{CV}$ events, after adjustment for age, sex, primary disease, APACHE II score, use of mechanical support devices, and length of C-ICU stay (adjusted HR: $2.23,95 \%$ CI $1.06-4.71 ; p=0.035$ ) (Table 2 ).

\section{Discussion}

The principal finding of our study was that GI bleeding during C-ICU admission in patients with CV diseases requiring intensive care was associated with subsequent $\mathrm{CV}$ events after C-ICU discharge. The patients' characteristics differed significantly between the GI bleeding and non-GI bleeding groups, with a higher prevalence 
Table 1 Clinical characteristics and co-interventions in patients with and without GI bleeding
GI bleeding $(n=27)$ Non-GI bleeding $p$ value $(n=465)$

\begin{tabular}{|c|c|c|c|}
\hline \multicolumn{4}{|l|}{ Demographics } \\
\hline Age (years) & $72.3 \pm 14.9$ & $70.8 \pm 14.6$ & $0.592 *$ \\
\hline Female sex, $n(\%)$ & $12(44.4)$ & $162(34.8)$ & 0.309 \\
\hline \multicolumn{4}{|l|}{ Medical history, $n(\%)$} \\
\hline Diabetes & $9(33.3)$ & $169(36.3)$ & 0.839 \\
\hline Hypertension & $21(77.8)$ & $363(78.1)$ & 1.000 \\
\hline Dyslipidemia & $15(55.6)$ & $263(56.6)$ & 1.000 \\
\hline Chronic kidney disease ( $\geq$ grade 3 ) & $19(70.4)$ & $264(56.8)$ & 0.161 \\
\hline Myocardial infarction & $2(7.4)$ & $75(16.1)$ & 0.286 \\
\hline Atrial fibrillation & 7 (25.9) & $69(14.8)$ & 0.164 \\
\hline Heart failure & $5(18.5)$ & $115(24.7)$ & 0.645 \\
\hline Hepatic disorders & $2(7.4)$ & $8(1.7)$ & 0.099 \\
\hline Gastroesophageal reflux disease & $0(0.0)$ & $15(3.2)$ & 1.000 \\
\hline Gastroduodenal ulcer & $2(7.4)$ & $17(3.7)$ & 0.280 \\
\hline Gastrointestinal bleeding & $2(7.4)$ & $12(2.6)$ & 0.176 \\
\hline Malignancy & $5(18.5)$ & $71(15.3)$ & 0.589 \\
\hline Smoking habit & $16(59.3)$ & $269(57.8)$ & 1.000 \\
\hline Percutaneous coronary intervention & $6(22.2)$ & $67(14.4)$ & 0.266 \\
\hline Coronary artery bypass grafting & $2(7.4)$ & $20(4.3)$ & 0.343 \\
\hline \multicolumn{4}{|l|}{ Medications before admission, $n(\%)$} \\
\hline Anticoagulant drugs & $6(22.2)$ & $54(11.6)$ & 0.124 \\
\hline Aspirin & $9(33.3)$ & $88(18.9)$ & 0.081 \\
\hline Clopidogrel & $1(3.7)$ & $33(7.1)$ & 1.000 \\
\hline Prasugrel & $1(3.7)$ & $7(1.5)$ & 0.365 \\
\hline Other anti-platelet drugs & $1(3.7)$ & $8(1.7)$ & 0.401 \\
\hline Steroids & $1(3.7)$ & $24(5.2)$ & 1.000 \\
\hline Proton pump inhibitors & $9(33.3)$ & $137(29.5)$ & 0.668 \\
\hline Histamine type 2 receptor antagonists & $1(3.7)$ & $18(3.9)$ & 1.000 \\
\hline \multicolumn{4}{|l|}{ Primary diseases, $n(\%)$} \\
\hline Acute coronary syndrome & $12(44.4)$ & $189(40.6)$ & 0.693 \\
\hline Heart failure & $5(18.5)$ & $107(23.0)$ & 0.813 \\
\hline Acute aortic dissection & $2(7.4)$ & $31(6.7)$ & 0.701 \\
\hline Emergency arrhythmia & $1(3.7)$ & $30(6.5)$ & 1.000 \\
\hline Pulmonary embolism & $1(3.7)$ & $3(0.6)$ & 0.203 \\
\hline Acute myocarditis & $0(0.0)$ & $7(1.5)$ & 1.000 \\
\hline Takotsubo cardiomyopathy & $0(0.0)$ & $12(2.6)$ & 1.000 \\
\hline Others & $6(22.2)$ & $86(18.5)$ & 0.614 \\
\hline \multicolumn{4}{|l|}{ Clinical features, $n(\%)$} \\
\hline Out-of-hospital cardiac arrest & $5(18.5)$ & $15(3.2)$ & 0.003 \\
\hline Cardiopulmonary arrest on arrival & $3(11.1)$ & $15(3.2)$ & 0.069 \\
\hline Shock vital (SBP < 90 mmHg) & $7(25.9)$ & $50(10.8)$ & 0.027 \\
\hline \multicolumn{4}{|l|}{ Severity score at admission (score) } \\
\hline SOFA score & $4.3 \pm 3.6$ & $2.8 \pm 3.2$ & $0.016^{*}$ \\
\hline APACHE II score & $20.2 \pm 8.2$ & $15.1 \pm 6.8$ & $<0.001 *$ \\
\hline \multicolumn{4}{|l|}{ Treatments during C-ICU admission, $n(\%)$} \\
\hline Anticoagulant drugs & $16(59.3)$ & $256(55.1)$ & 0.696 \\
\hline Single anti-platelet therapy & $3(11.1)$ & $91(19.6)$ & 0.448 \\
\hline Dual anti-platelet therapy & $10(37.0)$ & $161(34.6)$ & 0.836 \\
\hline Proton pump inhibitors & $27(100)$ & $384(82.6)$ & 0.013 \\
\hline Blood transfusion & $22(81.5)$ & $82(17.6)$ & $<0.001$ \\
\hline
\end{tabular}


Table 1 (continued)

\begin{tabular}{lllr}
\hline & GI bleeding $(n=27)$ & $\begin{array}{l}\text { Non-GI bleeding } \\
(n=465)\end{array}$ & $p$ value \\
\hline Percutaneous coronary intervention & $10(37.0)$ & $149(32.0)$ & 0.673 \\
Coronary artery bypass grafting & $0(0.0)$ & $19(4.1)$ & 0.615 \\
Other surgical interventions & $4(14.8)$ & $27(5.8)$ & 0.081 \\
Noninvasive positive pressure ventilation & $6(22.2)$ & $120(25.8)$ & 0.822 \\
Mechanical ventilator & $8(29.6)$ & $61(13.1)$ & 0.039 \\
Renal replacement therapy & $5(18.5)$ & $43(9.2)$ & 0.169 \\
Intra-aortic balloon pump & $4(14.8)$ & $53(11.4)$ & 0.539 \\
Percutaneous cardiopulmonary support & $2(7.4)$ & $15(3.2)$ & 0.238 \\
Impella ${ }^{\circledR}$ & $2(7.4)$ & $11(2.4)$ & 0.156 \\
Length of C-ICU stay (days) & $8[5-16]$ & $5[3-8]$ & $<0.001^{\dagger}$ \\
In-hospital adverse events & & & \\
Nosocomial pneumonia, $n(\%)$ & $3(11.1)$ & $18(3.9)$ & 0.101 \\
Clostridium difficile infection, $n(\%)$ & $1(3.7)$ & $0(0.0)$ & 0.055 \\
In-hospital mortality, $n(\%)$ & $0(0.0)$ & $34(7.3)$ & 0.244 \\
\hline
\end{tabular}

Data are presented as mean \pm standard deviation, $n(\%)$, or median [interquartile range]. Chronic kidney disease (stage G3), based on an estimated glomerular filtration rate $<60 \mathrm{ml} / \mathrm{min} / 1.73 \mathrm{~m}^{2}$

*Compared by Student's $t$ test; ${ }^{\dagger}$ compared by Mann-Whitney $U$ test

GI gastrointestinal, SBP systolic blood pressure, SOFA Sequential Organ Failure Assessment, APACHE Acute Physiology and Chronic Health Evaluation, $C$-ICU cardiovascular-intensive care unit

Fig. 2 Cumulative incidences of $\mathrm{CV}$ events as estimated by Kaplan-Meier analysis. $C V$ cardiovascular, GI gastrointestinal, $C-I C U$ cardiovascular-intensive care unit

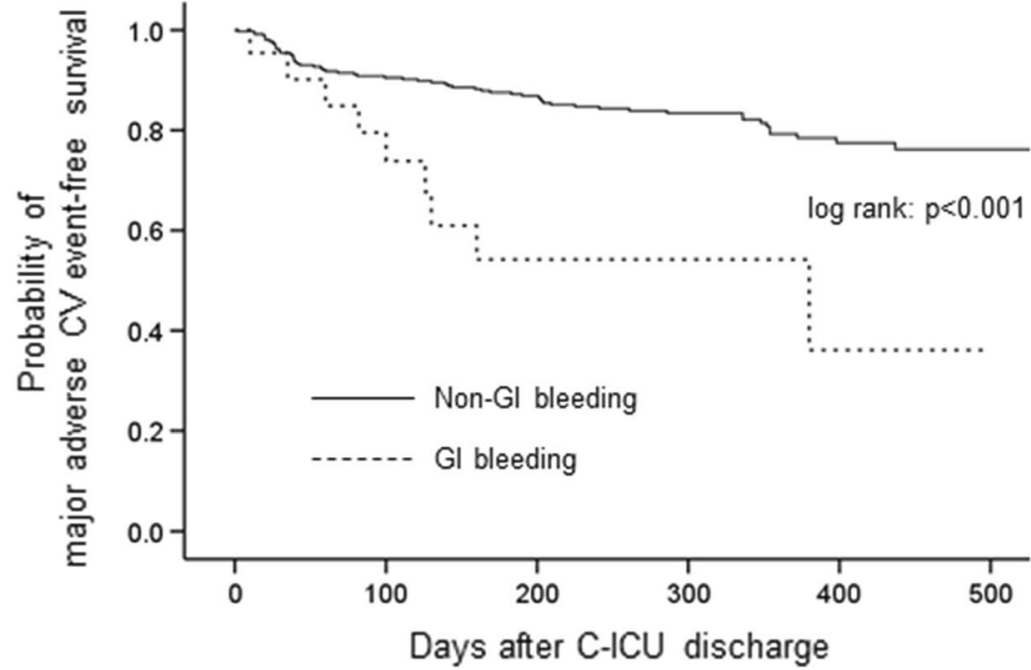

Number at risk: Patients

$\begin{array}{rcccccc}\text { Non-Gl bleeding } & 427 & 283 & 249 & 159 & 78 & 20 \\ \text { Gl bleeding } & 26 & 13 & 7 & 4 & 2 & 0\end{array}$

of unfavorable characteristics noted in the GI bleeding group, including a higher severity on admission, higher frequency of mechanical ventilators usage, and a longer C-ICU admission duration. GI bleeding occurs more frequently in ACS patients with severe clinical symptoms and is associated with more advanced age, baseline anemia, diabetes, and chronic renal insufficiency [5, 11-15]. These findings, in combination with ours, raise the possibility that GI bleeding is a clinical feature of severe primary disease conditions associated with poor CV outcomes.

We also considered that GI bleeding in C-ICU patients was independently associated with long-term CV outcomes, as multivariate analyses demonstrated that GI bleeding was an independent risk factor for subsequent $\mathrm{CV}$ events, after adjustment for severity score, use of mechanical support devices, and length of C-ICU stay, all of which are known 
Table 2 Multivariable analysis with a Cox proportional hazards model for subsequent cardiovascular events

\begin{tabular}{lll}
\hline Variables & Adjusted HR (95\% CI) & $p$ value \\
\hline Age (years) & $1.03(1.00-1.05)$ & 0.024 \\
Male sex & $1.34(0.77-2.31)$ & 0.298 \\
Primary diseases (vs. acute coronary syndrome) & \\
$\quad$ Heart failure & $2.01(1.13-3.57)$ & 0.017 \\
Acute aortic dissection & $1.50(0.57-3.97)$ & 0.414 \\
Other cardiac diseases & $0.80(0.27-2.35)$ & 0.681 \\
Non-cardiac diseases & $1.75(0.78-3.91)$ & 0.175 \\
APACHE II score & $1.03(0.98-1.07)$ & 0.239 \\
Use of mechanical support devices & $0.91(0.48-1.73)$ & 0.762 \\
Gastrointestinal bleeding & $2.23(1.06-4.71)$ & 0.035 \\
Length of C-ICU stay (days) & $1.03(1.01-1.04)$ & 0.010 \\
\hline
\end{tabular}

$H R$ hazard ratio, $C I$ confidence interval, APACHE Acute Physiology and Chronic Health Evaluation, $C$-ICU cardiovascular-intensive care unit

to be associated with poorer outcomes $[4,16]$. Furthermore, the in-hospital mortality rates, which are reportedly more strongly associated with a patient's disease severity, did not differ between the GI bleeding and non-GI bleeding groups. Although the impact of bleeding on short-term mortality was significant and directly explained the fatal course of bleeding events with anemia or hypotension [17], the effects of bleeding on long-term prognoses remain controversial, and the mechanisms by which bleeding affects $\mathrm{CV}$ outcomes long after the bleeding events themselves remains unclear $[18,19]$. Blood transfusion is a possible reason for the association of bleeding events with long-term mortality and CV events, as it is linked to adverse effects such as the following: (1) increased platelet reactivity and procoagulant protein levels, (2) impaired oxygenation capability, (3) reduced transport rate of nitric oxide by transfused red blood cells, and (4) altered deformability of red blood cells during storage [20]. In the present study, blood transfusion was performed in more than $80 \%$ of patients with GI bleeding, and subsequent $\mathrm{CV}$ events were identified only in those who received blood transfusions. Although major bleeding is likely to require blood transfusion and is associated with poor outcomes, our results show that only $11 \%$ of the patients with GI bleeding who developed subsequent $\mathrm{CV}$ events had been categorized as having major bleeding. Previous reports also indicated that provision of blood transfusion to patients with GI bleeding negatively affects their long-term $\mathrm{CV}$ outcomes, regardless of the severity of bleeding $[21,22]$. The formulation of a restrictive blood transfusion strategy should be considered for the treatment of anemia [23, 24]. On the other hand, the presence of anemia is known to increase the risks of death and $\mathrm{CV}$ events in patients with cardiac disease after surgery, critically ill patients, and ACS patients [25-27]. Appropriate blood transfusion criteria is required for such cases.
The incidence rates of GI bleeding in our C-ICU, as real world data, did not differ between primary diseases, and were higher than those reported in a prospective randomized study limited to ACS patients [5]. Initially, we expected that ACS patients would have a higher rate of GI bleeding than patients with other CV diseases, as all ACS patients receive anti-platelet drugs, usually as dual anti-platelet therapy, immediately after diagnosis. However, our results differed from this initial expectation, and the type of anti-platelet therapy used, such as single or dual anti-platelet therapy, did not affect the incidence of GI bleeding. This may be attributed to the high usage rate of prophylactic PPIs $(82.6 \%$ in the non-GI bleeding group) in our C-ICU based on our stress ulcer prophylaxis strategy, which potentially reduces the risk of GI bleeding due to anti-platelet drugs [28].

The prophylactic use of PPIs for stress ulcers in critically ill patients is still controversial [29]. In this study, we could not determine whether PPI administration was effective in preventing both GI bleeding and subsequent $\mathrm{CV}$ events in our specific C-ICU setting with a high rate of prophylactic PPI administration. It was also unclear whether PPI administration to outpatients could prevent GI bleeding after C-ICU admission. Stress-related mucosal erosions and subepithelial hemorrhage occurred within $24 \mathrm{~h}$ after admission in more than $70 \%$ of critically ill patients in the ICU [3]. Taken together with our dataset, in which GI bleeding occurred most frequently on the first day, the prompt administration of PPIs after C-ICU admission or a potassium-competitive acid blocker that can rapidly raise blood concentrations of PPIs may be effective in preventing the incidence of GI bleeding complications in patients with $\mathrm{CV}$ diseases requiring intensive care [30,31]. On the other hand, prophylactic administration of PPIs has not demonstrated a reduction in the mortality rate after 90 days in ICU patients who were at risk of GI bleeding, although it did reduce the incidence of clinically important GI bleeding [29]. Subsequent CV events after GI bleeding during C-ICU admission may not be reduced by the administration of PPIs in patients with acute $\mathrm{CV}$ diseases. Physicians should recognize GI bleeding as a risk factor of $\mathrm{CV}$ outcomes regardless of PPI administration in such cases.

The GI tract, including the upper and lower tracts, was the most frequently reported site of bleeding complications in patients admitted to the C-ICU in this study. In a previous report, vascular access sites were the most commonly noted sources of bleeding in patients with acute myocardial infarction who underwent percutaneous coronary intervention (PCI) [32]. Several factors have been suggested to underlie this difference. First, our study included several CV diseases, such as heart failure and acute aortic dissection, in addition to ACS requiring PCI. Second, changing the access site for PCI from the femoral to the radial artery may reduce the rates of bleeding complications involving the puncture 
site. Third, critically ill patients in the C-ICU were subjected to high levels of stress, increasing the risk of stress-related mucosal damage and resulting in gastroduodenal ulceration and GI bleeding [3, 33].

This study has several limitations owing to its retrospective design, small sample size, and single-center nature. We enrolled all patients admitted to the C-ICU, including non-cardiac patients with suspicions of $\mathrm{CV}$ disease at the time of admission. This population heterogeneity may have affected the outcomes of patients in this study, although the incidence rates of both GI bleeding complications while in the C-ICU and subsequent CV events were similar in our ACS and non-ACS patient groups. Heart failure was the main cause of both C-ICU admission and subsequent CV events. Therefore, as a co-variate of GI bleeding, it may have affected the result of the multivariate analysis in the present study, which showed a low incidence rate of the outcome. Second, we could not collect information on those who were transferred to other hospitals or who went to other hospitals after discharge. Thus, the outcomes of this study may have been underestimated. Third, the number of GI bleeding events may not have been accurately determined, as not all patients underwent GI endoscopy for the diagnosis of GI bleeding. However, GI bleeding events were documented as accurately as possible by the application of the TIMI bleeding criteria. Notably, the incidence of GI bleeding in this study was higher than that observed in a previous study [5]. Fourth, the mechanism by which GI bleeding is associated with CV events, unlike other bleeding complications, is yet to be fully clarified. The GI tract may merely be a source of bleeding. Furthermore, it was unclear whether GI bleeding after C-ICU discharge was a risk factor for subsequent CV events.

In conclusion, we demonstrated that GI bleeding during C-ICU admission was independently associated with subsequent $\mathrm{CV}$ events in $\mathrm{C}$-ICU patients who required care for acute CV disease. Therefore, reduction of the risk of GI bleeding is crucial in C-ICU settings.

Acknowledgements We are grateful to Dr. Katsuhito Kato (Department of Public Health, Nippon Medical School, Japan) for the advice on statistical analysis.

\section{Declarations}

Conflict of interest The authors declare that there are no conflicts of interest.

\section{References}

1. Gottlieb JE, Menashe PI, Cruz E (1986) Gastrointestinal complications in critically ill patients: the intensivists' overview. Am J Gastroenterol 81(4):227-238
2. Cook DJ, Fuller HD, Guyatt GH, Marshall JC, Leasa D, Hall R, Winton TL, Rutledge F, Todd TJ, Roy P, Lacroix J, Griffith L, Willan A (1994) Risk factors for gastrointestinal bleeding in critically ill patients. N Engl J Med 330(6):377-381

3. Mutlu GM, Mutlu EA, Factor P (2001) GI complications in patients receiving mechanical ventilation. Chest 119(4):1222-1241

4. Cook DJ, Griffith LE, Walter SD, Guyatt GH, Meade MO, Heyland DK, Kirby A, Tryba M, Canadian Critical Care Trials Group (2001) The attributable mortality and length of intensive care unit stay of clinically important gastrointestinal bleeding in critically ill patients. Crit Care 5(6):368-375

5. Nikolsky E, Stone GW, Kirtane AJ, Dangas GD, Lansky AJ, McLaurin B, Lincoff AM, Feit F, Moses JW, Fahy M, Manoukian SV, White HD, Ohman EM, Bertrand ME, Cox DA, Mehran $\mathrm{R}$ (2009) Gastrointestinal bleeding in patients with acute coronary syndromes: incidence, predictors, and clinical implications: analysis from the ACUITY (acute catheterization and urgent intervention triage strategy) trial. J Am Coll Cardiol 54(14):1293-1302

6. Abbas AE, Brodie B, Dixon S, Marsalese D, Brewington S, O'Neill WW, Grines LL, Grines CL (2005) Incidence and prognostic impact of gastrointestinal bleeding after percutaneous coronary intervention for acute myocardial infarction. Am J Cardiol 96(2): 173-176

7. Bovill EG, Terrin ML, Stump DC, Berke AD, Frederick M, Collen D, Feit F, Gore JM, Hillis LD, Lambrew CT, Leiboff R, Mann KG, Markis JE, Pratt CM, Sharkey SW, Sopko G, Tracy RP, Chesebro JH (1991) Hemorrhagic events during therapy with recombinant tissue-type plasminogen activator, heparin, and aspirin for acute myocardial infarction. Results of the thrombolysis in myocardial infarction (TIMI), phase II trial. Ann Intern Med 115(4):256-265

8. Amsterdam EA, Wenger NK, Brindis RG, Casey DE Jr, Ganiats TG, Holmes DR Jr, Jaffe AS, Jneid H, Kelly RF, Kontos MC, Levine GN, Liebson PR, Mukherjee D, Peterson ED, Sabatine MS, Smalling RW, Zieman SJ, AATF Members (2014) 2014 AHA/ACC guideline for the management of patients with nonST-elevation acute coronary syndromes: a report of the American college of cardiology/American heart association task force on practice guidelines. Circulation 130(25):2354-2394

9. Ibanez B, James S, Agewall S, Antunes MJ, Bucciarelli-Ducci C, Bueno H, Caforio ALP, Crea F, Goudevenos JA, Halvorsen S, Hindricks G, Kastrati A, Lenzen MJ, Prescott E, Roffi M, Valgimigli M, Varenhorst C, Vranckx P, Widimsky P, Group ESCSD (2018) 2017 ESC guidelines for the management of acute myocardial infarction in patients presenting with ST-segment elevation: the task force for the management of acute myocardial infarction in patients presenting with ST-segment elevation of the European society of cardiology (ESC). Eur Heart J 39(2):119-177

10. Suh JW, Mehran R, Claessen BE, Xu K, Baber U, Dangas G, Parise H, Lansky AJ, Witzenbichler B, Grines CL, Guagliumi G, Kornowski R, Wohrle J, Dudek D, Weisz G, Stone GW (2011) Impact of in-hospital major bleeding on late clinical outcomes after primary percutaneous coronary intervention in acute myocardial infarction the HORIZONS-AMI (harmonizing outcomes with revascularization and stents in acute myocardial infarction) trial. J Am Coll Cardiol 58(17):1750-1756

11. Nikolsky E, Aymong ED, Halkin A, Grines CL, Cox DA, Garcia E, Mehran R, Tcheng JE, Griffin JJ, Guagliumi G, Stuckey T, Turco M, Cohen DA, Negoita M, Lansky AJ, Stone GW (2004) Impact of anemia in patients with acute myocardial infarction undergoing primary percutaneous coronary intervention: analysis from the controlled abciximab and device investigation to lower late angioplasty complications (CADILLAC) trial. J Am Coll Cardiol 44(3):547-553

12. Avezum A, Makdisse M, Spencer F, Gore JM, Fox KA, Montalescot G, Eagle KA, White K, Mehta RH, Knobel E, Collet 
JP, GRACE Investigators (2005) Impact of age on management and outcome of acute coronary syndrome: observations from the global registry of acute coronary events (GRACE). Am Heart J 149(1):67-73

13. Keough-Ryan TM, Kiberd BA, Dipchand CS, Cox JL, Rose CL, Thompson KJ, Clase CM (2005) Outcomes of acute coronary syndrome in a large Canadian cohort: impact of chronic renal insufficiency, cardiac interventions, and anemia. Am J Kidney Dis 46(5):845-855

14. Feit F, Manoukian SV, Ebrahimi R, Pollack CV, Ohman EM, Attubato MJ, Mehran R, Stone GW (2008) Safety and efficacy of bivalirudin monotherapy in patients with diabetes mellitus and acute coronary syndromes: a report from the ACUITY (acute catheterization and urgent intervention triage strategy) trial. J Am Coll Cardiol 51(17):1645-1652

15. Spencer FA, Moscucci M, Granger CB, Gore JM, Goldberg RJ, Steg PG, Goodman SG, Budaj A, FitzGerald G, Fox KA, GRACE Investigators (2007) Does comorbidity account for the excess mortality in patients with major bleeding in acute myocardial infarction? Circulation 116(24):2793-2801

16. Li L, Geraghty OC, Mehta Z, Rothwell PM, Vascular SO (2017) Age-specific risks, severity, time course, and outcome of bleeding on long-term antiplatelet treatment after vascular events: a population-based cohort study. Lancet 390(10093):490-499

17. Rao SV (2015) The conundrum of reducing ischemic and bleeding events after PCI. J Am Coll Cardiol 65(14):1421-1423

18. Kikkert WJ, Zwinderman AH, Vis MM, Baan J Jr, Koch KT, Peters RJ, de Winter RJ, Piek JJ, Tijssen JG, Henriques JP (2013) Timing of mortality after severe bleeding and recurrent myocardial infarction in patients with ST-segment-elevation myocardial infarction. Circ Cardiovasc Interv 6(4):391-398

19. Cornara S, Somaschini A, De Servi S, Crimi G, Ferlini M, Baldo A, Camporotondo R, Gnecchi M, Ormezzano MF, Oltrona Visconti L, De Ferrari GM (2017) Prognostic impact of in-hospital-bleeding in patients with ST-elevation myocardial infarction treated by primary percutaneous coronary intervention. Am J Cardiol 120(10):1734-1741

20. Kwok CS, Sherwood MW, Watson SM, Nasir SB, Sperrin M, Nolan J, Kinnaird T, Kiatchoosakun S, Ludman PF, de Belder MA, Rao SV, Mamas MA (2015) Blood transfusion after percutaneous coronary intervention and risk of subsequent adverse outcomes: a systematic review and meta-analysis. JACC Cardiovasc Interv 8(3):436-446

21. Kinnaird TD, Stabile E, Mintz GS, Lee CW, Canos DA, Gevorkian N, Pinnow EE, Kent KM, Pichard AD, Satler LF, Weissman NJ, Lindsay J, Fuchs S (2003) Incidence, predictors, and prognostic implications of bleeding and blood transfusion following percutaneous coronary interventions. Am J Cardiol 92(8):930-935

22. Sherwood MW, Wang Y, Curtis JP, Peterson ED, Rao SV (2014) Patterns and outcomes of red blood cell transfusion in patients undergoing percutaneous coronary intervention. JAMA 311(8):836-843

23. Salpeter SR, Buckley JS, Chatterjee S (2014) Impact of more restrictive blood transfusion strategies on clinical outcomes: a meta-analysis and systematic review. Am J Med 127(2):124-131. e3

24. Hebert PC, Wells G, Blajchman MA, Marshall J, Martin C, Pagliarello G, Tweeddale M, Schweitzer I, Yetisir E (1999) A multicenter, randomized, controlled clinical trial of transfusion requirements in critical care. Transfusion requirements in critical care investigators, Canadian critical care trials group. $\mathrm{N}$ Engl $\mathbf{J}$ Med 340(6):409-417
25. Carson JL, Duff A, Poses RM, Berlin JA, Spence RK, Trout R, Noveck H, Strom BL (1996) Effect of anaemia and cardiovascular disease on surgical mortality and morbidity. Lancet 348(9034):1055-1060

26. Hebert PC, Wells G, Tweeddale M, Martin C, Marshall J, Pham B, Blajchman M, Schweitzer I, Pagliarello G (1997) Does transfusion practice affect mortality in critically ill patients? Transfusion requirements in critical care (TRICC) investigators and the Canadian critical care trials group. Am J Respir Crit Care Med 155(5):1618-1623

27. Sabatine MS, Morrow DA, Giugliano RP, Burton PB, Murphy SA, McCabe CH, Gibson CM, Braunwald E (2005) Association of hemoglobin levels with clinical outcomes in acute coronary syndromes. Circulation 111(16):2042-2049

28. Bhatt DL, Cryer BL, Contant CF, Cohen M, Lanas A, Schnitzer TJ, Shook TL, Lapuerta P, Goldsmith MA, Laine L, Scirica BM, Murphy SA, Cannon CP, COGENT Investigator (2010) Clopidogrel with or without omeprazole in coronary artery disease. $\mathrm{N}$ Engl J Med 363(20):1909-1917

29. Krag M, Marker S, Perner A, Wetterslev J, Wise MP, Schefold JC, Keus F, Guttormsen AB, Bendel S, Borthwick M, Lange T, Rasmussen BS, Siegemund M, Bundgaard H, Elkmann T, Jensen JV, Nielsen RD, Liboriussen L, Bestle MH, Elkjaer JM, Palmqvist DF, Backlund M, Laake JH, Badstolokken PM, Gronlund J, Breum O, Walli A, Winding R, Iversen S, Jarnvig IL, White JO, Brand B, Madsen MB, Quist L, Thornberg KJ, Moller A, Wiis J, Granholm A, Anthon CT, Meyhoff TS, Hjortrup PB, Aagaard SR, Andreasen JB, Sorensen CA, Haure P, Hauge J, Hollinger A, Scheuzger J, Tuchscherer D, Vuilliomenet T, Takala J, Jakob SM, Vang ML, Paelestik KB, Andersen KLD, van der Horst ICC, Dieperink W, Fjolner J, Kjer CKW, Solling C, Solling CG, Karttunen J, Morgan MPG, Sjobo B, Engstrom J, Agerholm-Larsen B, Moller MH, SUP-ICU Trial Group (2018) Pantoprazole in patients at risk for gastrointestinal bleeding in the ICU. N Engl $\mathrm{J}$ Med 379(23):2199-2208

30. Ye Z, Reintam Blaser A, Lytvyn L, Wang Y, Guyatt GH, Mikita JS, Roberts J, Agoritsas T, Bertschy S, Boroli F, Camsooksai J, Du B, Heen AF, Lu J, Mella JM, Vandvik PO, Wise R, Zheng Y, Liu L, Siemieniuk RAC (2020) Gastrointestinal bleeding prophylaxis for critically ill patients: a clinical practice guideline. BMJ 368:16722

31. Kawai T, Oda K, Funao N, Nishimura A, Matsumoto Y, Mizokami Y, Ashida K, Sugano K (2018) Vonoprazan prevents low-dose aspirin-associated ulcer recurrence: randomised phase 3 study. Gut 67(6):1033-1041

32. Nakamura M, Yamagishi M, Ueno T, Hara K, Ishiwata S, Itoh T, Hamanaka I, Wakatsuki T, Sugano T, Kawai K, Kimura T (2013) Current antiplatelet therapy for Japanese patients with ST elevation acute myocardial infarction: J-AMI registry. Cardiovasc Interv Ther 28(2):162-169

33. Krag M, Perner A, Wetterslev J, Wise MP, Borthwick M, Bendel S, McArthur C, Cook D, Nielsen N, Pelosi P, Keus F, Guttormsen AB, Moller AD, Moller MH, SUP-ICU Co-Authors (2015) Prevalence and outcome of gastrointestinal bleeding and use of acid suppressants in acutely ill adult intensive care patients. Intensive Care Med 41(5):833-845

Publisher's Note Springer Nature remains neutral with regard to jurisdictional claims in published maps and institutional affiliations. 